DOI: $10.7242 / 2658-705 \mathrm{X} / 2019.2 .2$

УДК 550.834

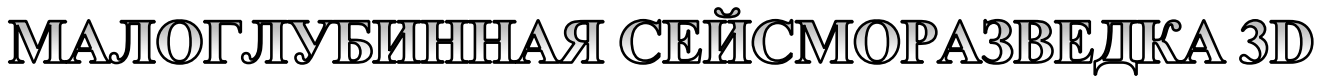 IHA YYULACTIKAX CO CJIOHKTHUIMI

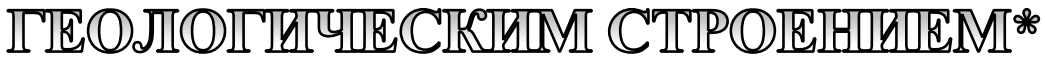

И.А. Санфиров, Горный институт УрО РАН

А.А. Жикин, Горный институт УрО РАН

А.Г. Ярославцев, Горный институт УрО РАН

А.И. Бабкин, Горный институт УрО РАН

А.В. Чугаев, Горный институт УрО РАН

И.Ю. Герасимова, Горный институт УрО РАН

Разработка водорастворимого месторождения в интервале малых глубин требует обеспечения надежными средствами прогнозирования прочностных свойств и контроля состояния как промышленных пластов, так и перекрывающей толщи. Представлена оценка возможностей новых методических решений по выявлению особенностей геологического строения, влияющих на безопасность подземной разработки Верхнекамского месторождения калийных солей.

Ключевые слова: пространственные системы регистрации данных сейсморазведки, сейсморазведка $3 D$.

Территория Пермского края имеет существенный минерально-ресурсный потенциал, где основную товарную ценность на региональном рынке определяют калийные и магниевые соли. Удельный вес Верхнекамского месторождения калийных и магниевых солей (ВКМКС) в ценности недр региона выглядит подавляющим и достигает $88 \%$.

Специфика обеспечения безопасной разработки данного месторождения заключается в сохранности водозащитной толщи (B3Т), разграничивающей промышленные пласты солей с вышележащими толщами водонапорных горизонтов. В случае нарушения В3Т по причинам наличия структурно-геологических неоднородностей или не соблюдения проектных планов ведения горных работ происходит прорыв подземных вод в горные выработки, что приводит к неизбежной потере рудника и разрабатываемых запасов полезного ископаемого.

Сейсморазведочные исследования, входящие в комплекс геолого-геофизического контроля процессов разработки и эксплуатации месторождения, с высокой степенью достоверности позволяют выявлять физико-геологические индикаторы состояния массива и их критические значения, при превышении которых возникает то или иное опасное состояние, что может быть часто интерпретировано как предвестник грядущей катастрофы [2, с. 16-24].

На сегодняшний день выявление потенциально опасных участков в преде-

\footnotetext{
* Работа выполнена при поддержке РФФИ (грант №16-45-590050-р_a-05).
} 
лах территории ВКМКС с привлечением опережающих и мониторинговых исследований ведется в основном по технологиям сейсморазведочных наблюдений $2 \mathrm{D}$ в рамках методики общей глубинной точки (ОГТ) [1, 2, 5].

Усложнение горно-геологических условий в пределах новых лицензионных участков ВКМКС обусловливает необходимость поиска новых методических решений по прогнозированию особенностей геологического строения, влияющих на безопасность подземной разработки залежей.

В рамках данного направления Горный институт УрО РАН совместно с Российским фондом фундаментальных исследований (РФФИ) и Правительством Пермского края реализовал проект, направленный на разработку пространственных систем регистрации сейсморазведочных данных (3D) с целью повышения достоверности определения структурно-физических параметров породного массива, испытывающего значимое антропогенное воздействие.

С целью решения поставленной задачи в качестве опытного полигона выбран участок в северной части месторождения. Территория участка холмистая, с перепадом абсолютных отметок рельефа от 170 до 200 м. Более 60\% площади представлено вырубками и сельскохозяйственными угодьями. Остальную часть площади занимает лес. Грунты песчаные, супесчаные, суглинистые, глинистые, подстилающий слой - глина. Во влажном состоянии они затрудняют передвижение транспорта вне дорог.

В тектоническом отношении участок исследования расположен на северном склоне крупной рифогенной структуры девонского возраста. Более подробно особенности геологического строения представлены на рис. 1.

По данным сейсморазведочных исследований 2D прошлых лет, в пределах выбранной площади выделено несколько аномальных участков. На окончательных временных разрезах (рис. 2) выделен ряд отражающих горизонтов (ОГ). Они, в соответствии с результатами скоростно- го анализа и геологоразведочными данными, приурочены к кровлям: соляномергельной толщи (СМТ), переходной пачки (ПП), карналлитового пласта $\mathrm{E}$, сильвинитовой пачки (Сил.) и к интервалу маркирующей глины (МГ).

По особенностям волновых картин (см. рис. 2), их параметров и количественным оценкам структурно-физических параметров предположено преобладающее влияние тектонического фактора на возникновение указанных участков. Структурная привязка отражающих границ в пределах изучаемого участка контролируется данными скважины 11 (рис. 3).

С учетом априорной геолого-геофизической информации построена объемная

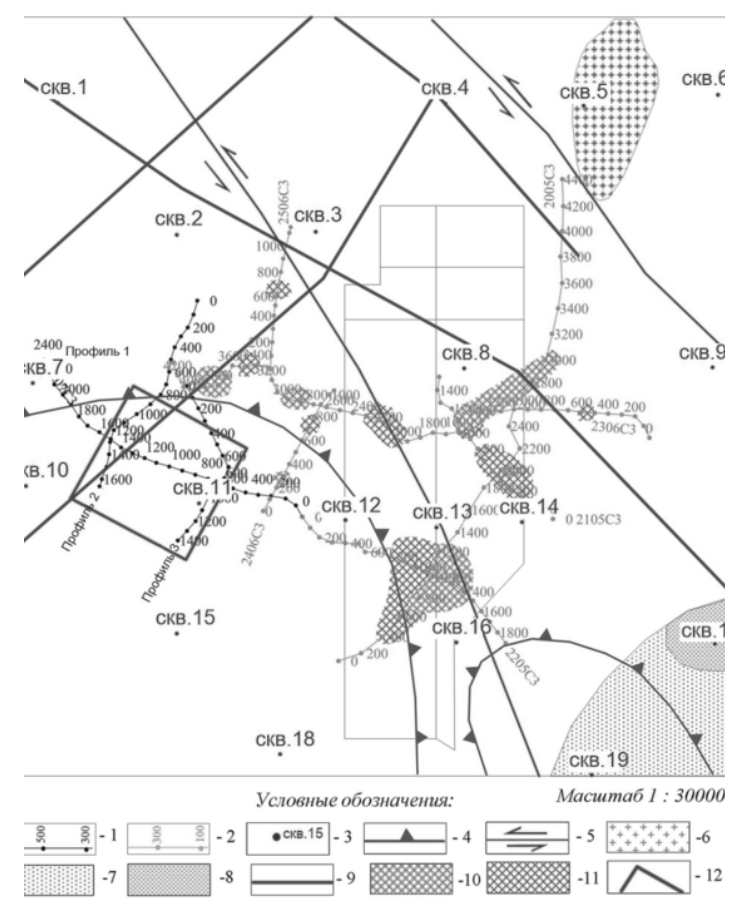

Рис. 1. Обзорная схема района исследований

1 - сейсмические профили; 2 - сейсмические профили прошльх лет; 3 - скважина; 4 - граница органогенных построек позднедевонского возраста; 5-сдвиг;

6 - зона замещения продуктивных пластов каменной солью; 7 - зона отсутствия карналлитовой зоньг; 8-зона отсутствия сильвинитовой зонь; аномалии волновой картины, выявленные по исследованиям прошльх лет: 9 - в продуктивной толще, 10 - в надсоляных отложениях;

11 - аномалии волновой картины, выявленные по исследованиям, 12 -участок проектирования сейсморазведочных исследований $3 D$ 


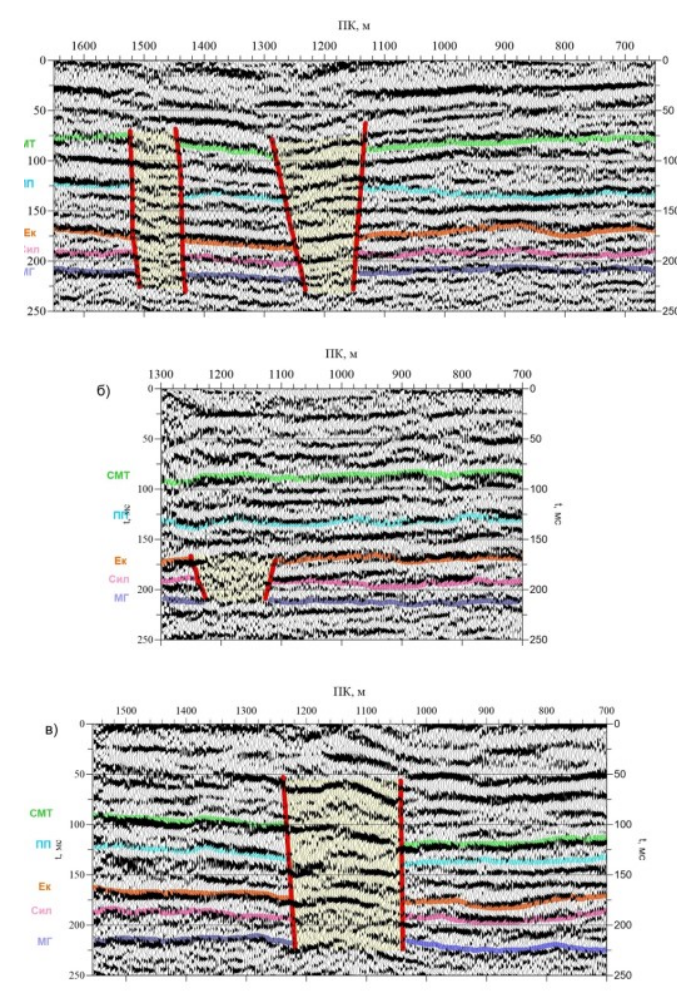

Рис. 2. Фрагменты временных разрезов

ОГТ по профилям, проходящих через участок проектирования сейсморазведочных исследований 3D: а) профиль 1 , б) профиль 2, в) профиль 3

детальная геологическая

модель

(см. рис. 3). Для расчета полученной модели использовались данные 18 скважин, вскрывшие следующие геологические границы (кровли): теригенно-карбонатная

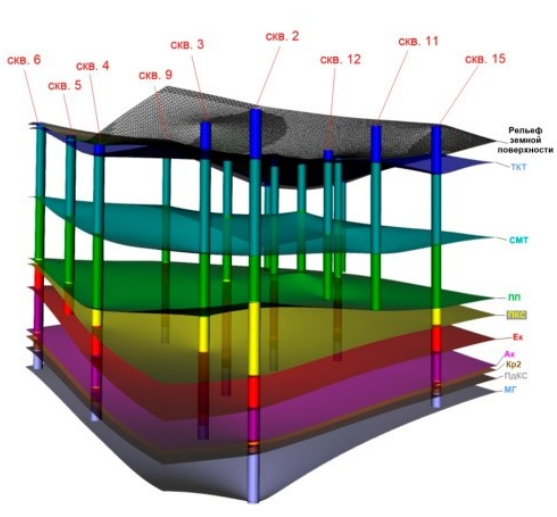

Рис. 3. Трехмерная геологическая модель района проектирования сейсморазведочных исследований $3 D$

толща (ТКТ), соляно-мергельная толща (CMT), переходная пачка (ПП), покровная каменная соль (ПКС), карналитовый пласт Е (Ек), сильвинитовый пласт А (Ак), сильвинитовый пласт Кр2 (Кр2), подстилающая каменная соль (ПдКС), маркирующая глина (МГ). Из анализа представленной модели следует, что пласты залегают субгоризонтально, с незначительным погружением $\left(5-15^{\circ}\right)$ с востока на запад.

Математическое моделирование волнового поля осуществлялось на основе упрощенной сейсмогеологической модели, включающей в себя наиболее динамически выраженные в волновом поле геологические границы, представленные на рис. 4.

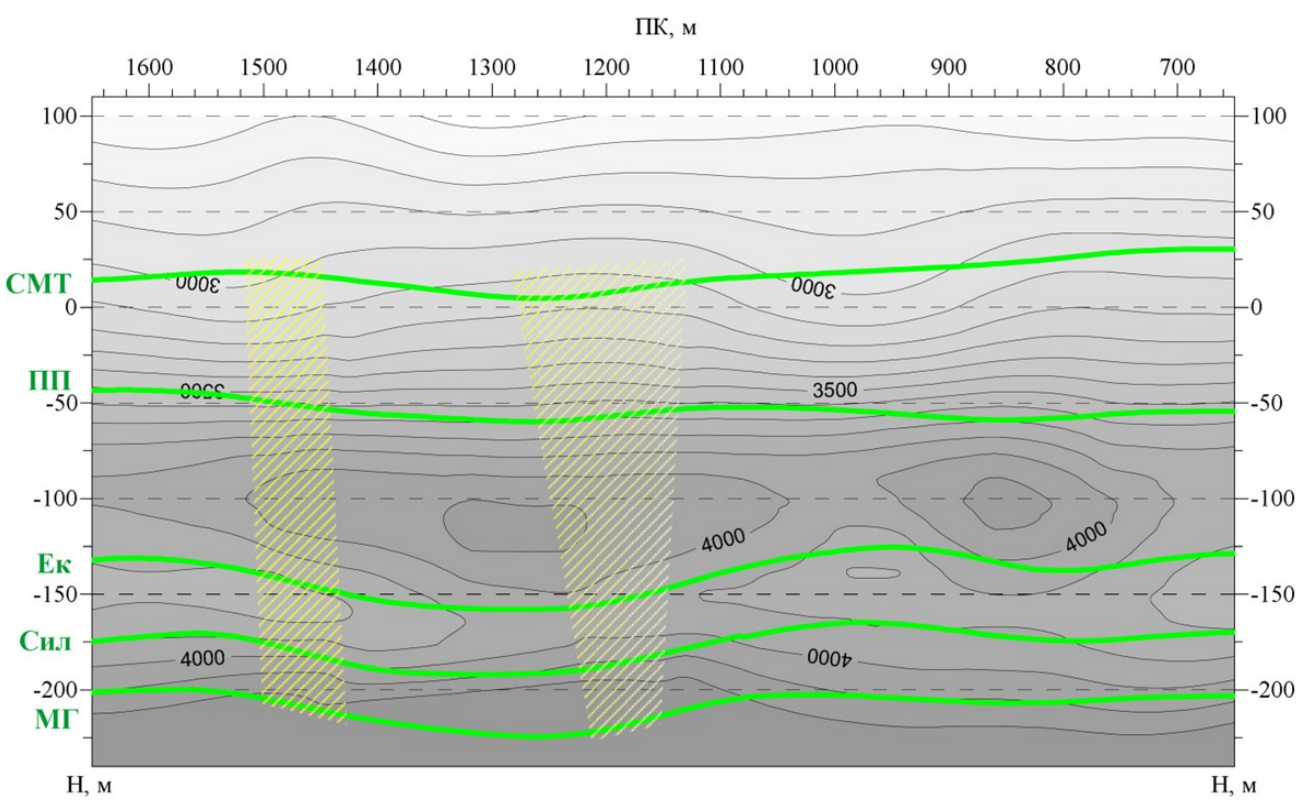

Рис. 4. Сейсмогеологическая модель, построенная по профилю 1 , расположенному на участке проектирования сейсморазведочных исследований $3 D$ 
С учетом имеющихся материальнотехнических и аппаратурных возможностей рассчитаны параметры системы пространственной регистрации. Определены следующие основные параметры: кратность - не менее 16, размер бина $\mathrm{B}_{\mathrm{x}, \mathrm{y}}-$ 8 м, канальность - 288 каналов, максимальное удаление $\mathrm{X}_{\max } \sim 400$ м, максимально минимальное удаление $\max \mathrm{X}_{\min }<$ 80 м. С учетом этих значений рассчитан шаблон, так называемый элементарный фрагмент 3D-системы наблюдения (рис. 5), состоящий из 6 линий приема (ЛПП) по 48 каналов в каждой, и 5 линий возбуждения (ЛПВ) по 13 пунктов возбуждения (ПВ). Расстояние между линиями приема $\triangle Л П П=64$ м, расстояние между линиями возбуждения $\triangle Л П В=64$ м

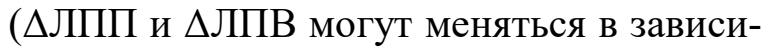
мости от возможности положения профилей на определенном участке работ).

В результате для реальных условий в пределах выбранного участка спроектирована 3D-система наблюдений со следующими параметрами (таблица):

При перемещении шаблона (рис. 5) по площади трехмерной съемки перекрытие происходит как по ЛПВ, так и по ЛПП.

\begin{tabular}{|c|c|}
\hline \multicolumn{2}{|c|}{$\begin{array}{c}\text { Параметры 3D-системы наблюдений } \\
\text { на участке исследований }\end{array}$} \\
\hline $\begin{array}{l}\text { Размер бина в направлении } \\
\text { in-line }\left(\mathrm{B}_{\mathrm{x}}\right), \mathrm{M}\end{array}$ & 8 \\
\hline $\begin{array}{c}\text { Размер бина в направлении } \\
\text { cross-line }\left(B_{y}\right), \text { м }\end{array}$ & 8 \\
\hline Шаг $\Delta П П, ~ м ~$ & 8 \\
\hline Шаг $\Delta \Pi \mathrm{B}, \mathrm{M}$ & 16 \\
\hline Количество активных каналов & 288 \\
\hline Число линий приема ( $\mathrm{N}_{\text {лпп) }}$ & 15 \\
\hline Число линий возбуждения (лпв) & 14 \\
\hline $\begin{array}{c}\left.\text { Общее число ПВ ( } \mathrm{N}_{п \mathrm{~B}}\right) \text { с учетом } \\
\text { перекрытий шаблонов }\end{array}$ & 960 \\
\hline $\begin{array}{c}\text { Общее число ПП (Nпп) с учетом } \\
\text { перекрытий шаблонов }\end{array}$ & 1801 \\
\hline Максимальный вынос $\left(X_{\max }\right)$, м & 418 \\
\hline $\begin{array}{c}\text { Максимально минимальный } \\
\text { вынос }\left(\max X_{\min }\right), \text { м }\end{array}$ & 1 \\
\hline Общее количество сейсмограмм ОПВ & 960 \\
\hline Максимальная кратность & 41 \\
\hline $\begin{array}{c}\text { Площадь съемки с ненулевой } \\
\text { кратностью, км² }\end{array}$ & 0,75 \\
\hline Всего бинов & 16637 \\
\hline Всего трасс & 276336 \\
\hline
\end{tabular}

При отстреле полосы наблюдения (ПН) шаблон смещается на 3 ЛПВ (перекрытие 2 ЛПВ). При переходе на следующую ПН смещение шаблона происходит на 3 ЛПП (перекрытие 3 ЛПП). Таким образом, происходит покрытие площади работ заданной номинальной кратностью (рис. 6).

Оценка качества (равномерности) распределения параметров реализованной системы наблюдений проведена на основе математических алгоритмов программного комплекса обработки сейсморазведочных данных SPS-PC. Средняя кратность достигает 30 (рис. 7). Система имеет достаточно широкий диапазон удалений с большим количеством трасс (рис. 8). Максимальное число трасс приходится на диапазон удалений 50-300 м, что обеспечивает наилучшее прослеживание целевого интервала.

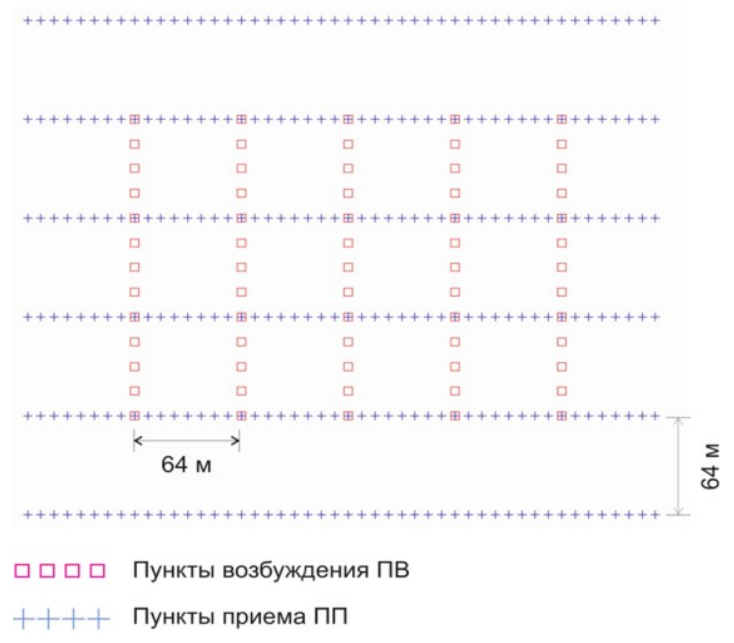

Рис. 5. Проектный шаблон отработки $3 D$

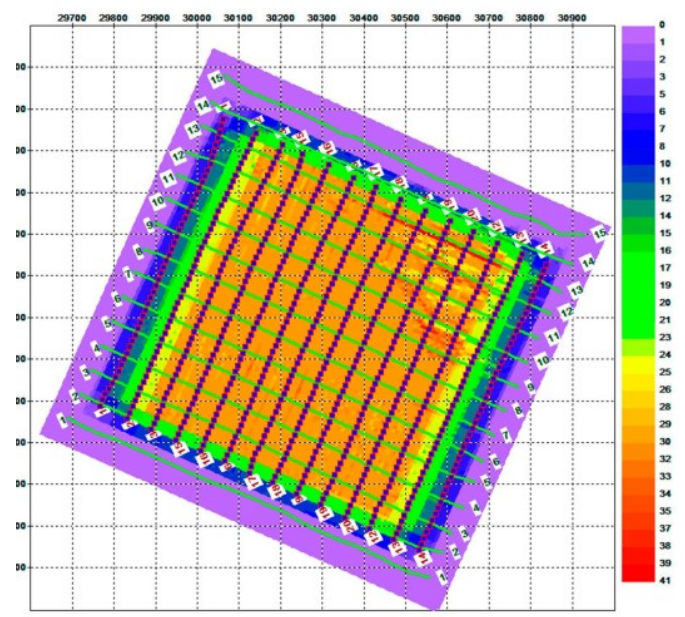

Рис. 6. Распределение номинальной кратности по площади

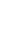

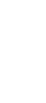


Анализируя обобщённый азимутальный спектр (зависимость числа трасс от азимута $\theta$ векторов, соединяющих ПВПП), можно заметить, что он обладает широким $\left(0-360^{\circ}\right)$ диапазоном азимутов и достаточно малым $(\Delta \theta<5)$ шагом их дискретизации (рис. 9). Это достигается благодаря использованию полномерной широкоазимутальной системы наблюдений. Трассы достаточно равномерно распределены по азимутам. Приближаясь к азимутам ориентации линий приема $\left(114^{\circ}\right.$ и $294^{\circ}$ ) наблюдаются резкие уменьшения количества трасс. Это обусловлено тем, что пункты возбуждения намеренно не проектировались на линиях приема.

Анализ характеристики направленности 3D-системы наблюдений (рис. 10) показывает, что ортогональные системы являются не самым оптимальным типом систем наблюдений для изучения азимутальной анизотропии. Но данный тип систем наблюдений наиболее технологичен и при некритичных требованиях к азимутальной выдержанности является оптимальным для наблюдений в пределах ВКМКС.

Несмотря на то что рассчитанная система наблюдений соответствует требованиям информативности для целевого интервала, при изучении интервала малых глубин в целевой области времен сосредоточены такие высокоинтенсивные регулярные помехи, как поверхностные, звуковая, преломленные и рефрагированные волны. В подобных условиях необходимо согласование расчётных параметров системы наблюдений с оптимальным окном прослеживания целевых волн на сейсмограммах. При необходимости целесообразна коррекция параметров системы наблюдений, подразумевающая смещение обобщенного спектра удалений в пространственные границы оптимального окна прослеживания отраженных волн. Данная коррекция возможна на основе решения прямой задачи.

Решение прямой задачи для проектируемой 3D-системы осуществлялось с использованием математического обеспечения для построения синтетических сейсмограмм объемной сейсморазведки - SPS-PC. Результаты упрощенной цифровой обработки набора синтетических сейсмограмм ОПВ для всей проектной площади исследований представлены на рис. 11. Упрощенный граф обработки состоял из процедур регулировки ампли-

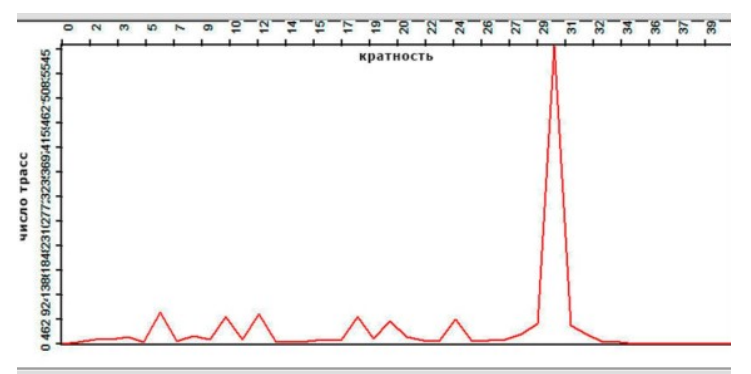

Рис. 7. Зависимость числа трасс от кратности

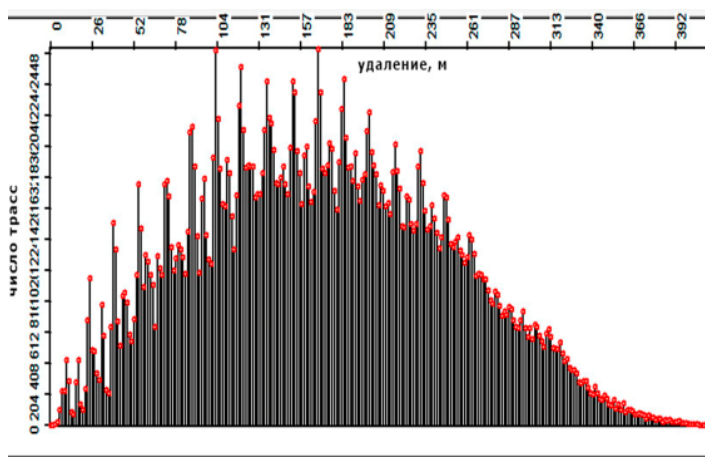

Рис. 8. Обобщенный спектр удалений

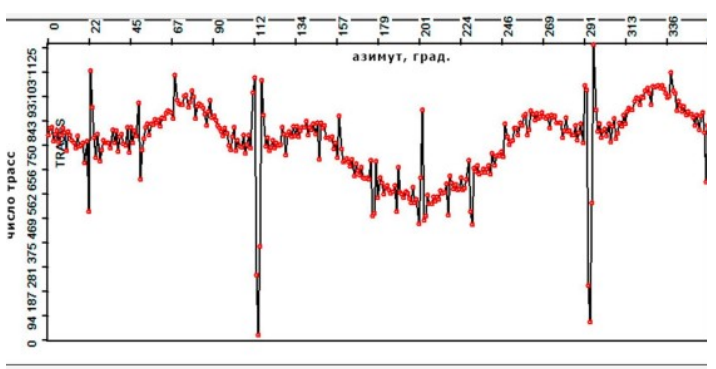

Рис. 9. Обобщенный спектр азимутов

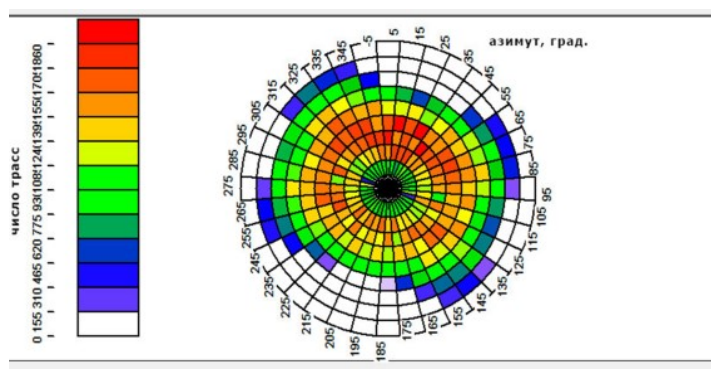

Рис. 10. Характеристика направленности системы наблюдений $3 D$ 


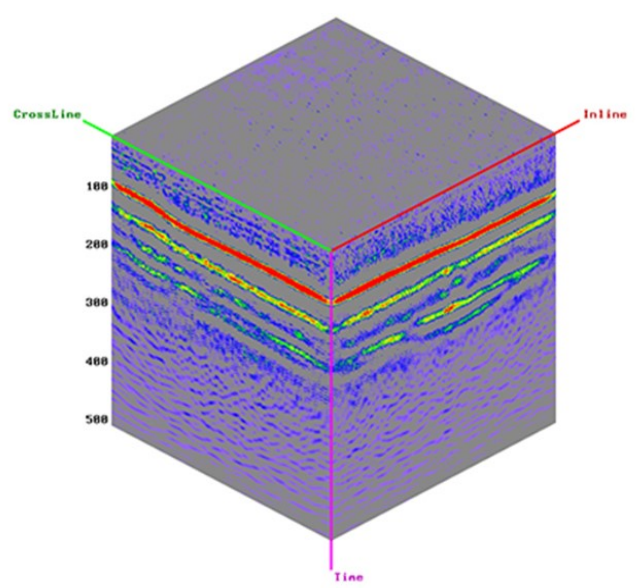

Рис. 11. Синтетический куб 3D для изучаемой площади

тудного уровня, ввода кинематических поправок и суммирования. На представленном кубе сейсмических данных основные отражающие горизонты имеют высокую динамическую выразительность. На основе полученного куба данных возможно разбиение объема модельной геологической среды на горизонтальные и вертикальные плоскости в различных направлениях (рис. 12).

Анализ полученных данных пространственной сейсморазведки интервала малых глубин указывает на высокую информативность модельного волнового поля, соответствие требуемой разрешенности и глубинности исследований, что в свою очередь, указывает на эффективность рассчитанной системы наблюдений.

Таким образом, для решения поставленных задач на площади 0.9 км $^{2}$ реализована 3D-система наблюдений в объеме 14 линий пунктов возбуждения и 15 линий пунктов приёма. Длина линий пунктов возбуждения $832 \mathrm{M}$, длина линий пунктов приема 952 м. Относительное расположение линий пунктов приема (ЛПП) и линий пунктов возбуждения (ЛПВ) представлено на рис. 13.

В отличие от полевых наблюдений $2 \mathrm{D}$, широко используемых при контроле состояния водозащитной толщи на территории ВКМКС в рамках невзрывной сейсморазведки высокого разрешения с применением интерференционной сис-

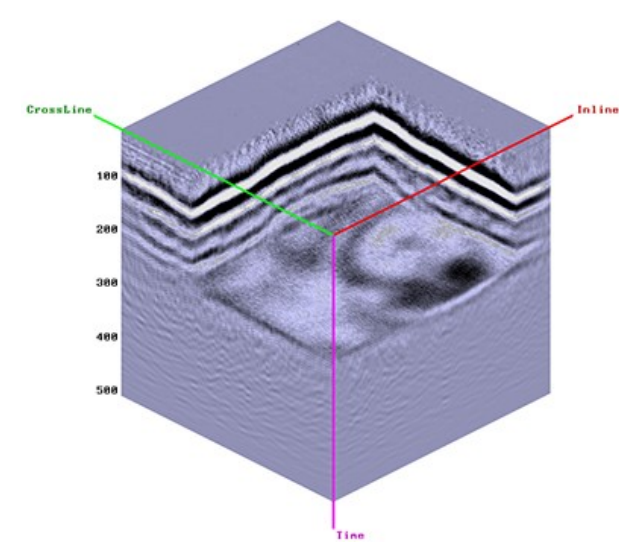

Рис. 12. Срезы трехмерного синтетического куба сейсмических данных после упрощенной цифрровой обработки

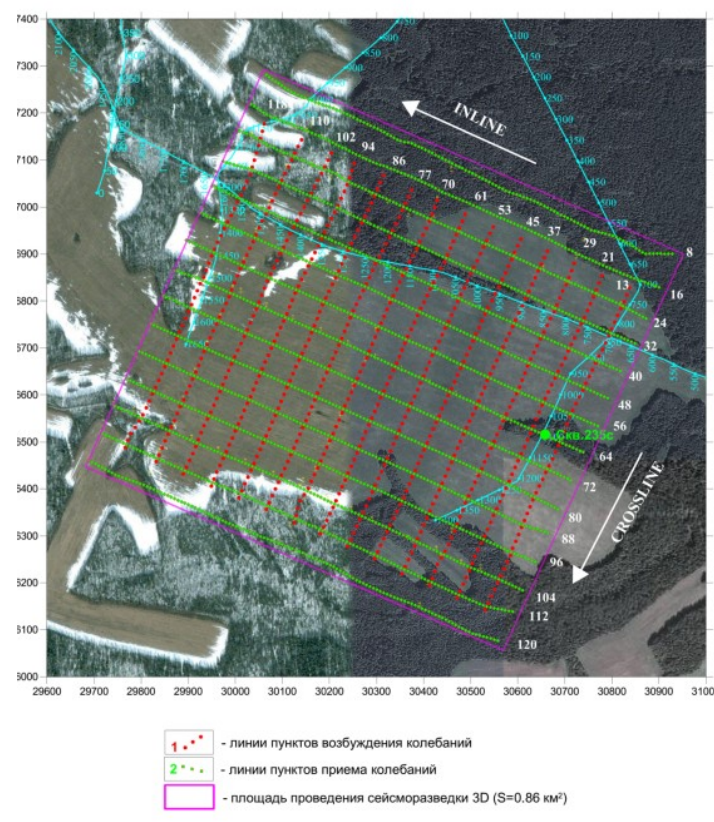

Рис. 13. Схема сейсморазведочных наблюдений $3 D$

темы по общей глубинной точке, сейсморазведочные 3D-исследования требуют наличия большего количества полевого персонала и средств регистрации колебаний. При этом временные затраты на отработку той же единицы площади увеличиваются в 5 раз. Кроме того, реализация системы наблюдений $3 \mathrm{D}$ требовала инструментальной планово-высотной привязки точек возбуждения и приема колебаний, что также привело к дополнительным временным затратам. 
Стоит отметить, что большой объем времени занимает подготовка данных к обработке. Кроме супервайзинга на полевом этапе требуется не только занесение координат в заголовки трасс, но и правильное описание реляционных связей между трассами во входящем наборе первичных записей. Успешное выполнение данной процедуры возможно при непосредственном взаимодействии специалистов, проектирующих систему, руководителя полевого отряда и оператора сейсмостанции. Пример полевой сейсмограммы по общему пункту возбуждения (ОПВ) представлен на рис. 14, а. На этапе подготовки набора данных к обработке и интерпретации коллективом авторов выполнен расчет априорных значений скоростей в верхней части разреза (ВЧР) на основании годографов первых вступлений на выборках трасс ОПВ, сформированных в направлении InLine. Для получения более точных значений статических поправок скорости ВЧР интерполировались по площади (расчет сеток в программе Surfer) и сглаживались (рис. 15).

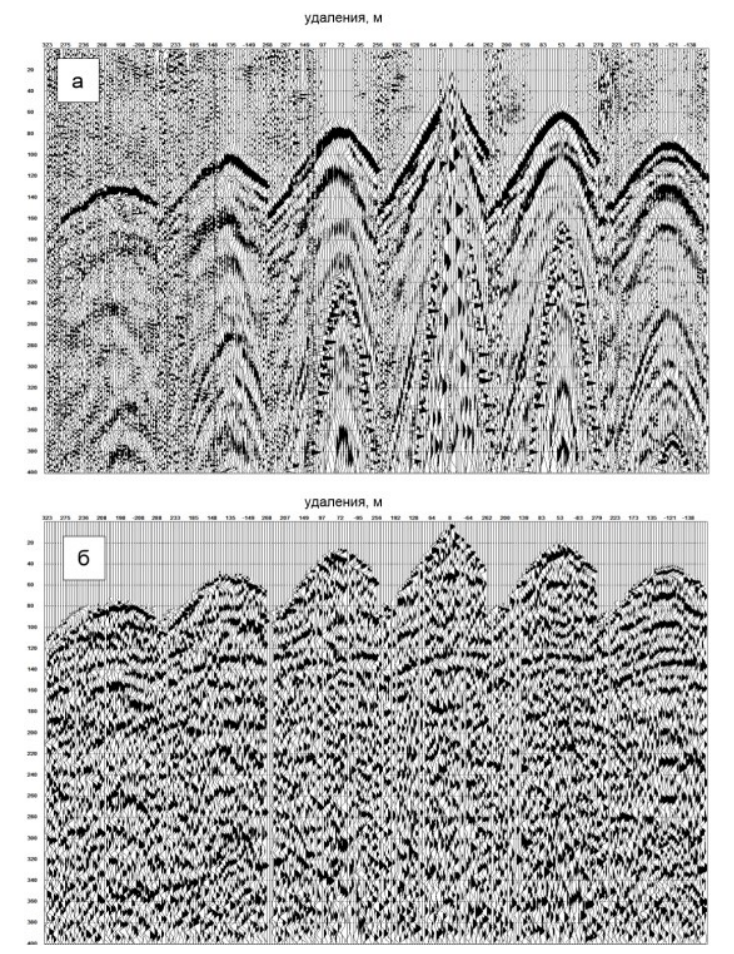

Рис. 14. Наблюдения 3D. Пример сейсмограммы ОПВ(ПК7440): $a$-исходная(без статики), б-после обработки (статика введена, кинематика вычтена)
После этого с учетом поверхности рельефа осуществлялся площадной пересчет мощностей ВЧР в вертикальные времена до уровня приведения (+140 м).

Обработка сейсморазведочных данных реализована в рамках имеющихся в «ГИ УрО РАН» обрабатывающих систем - SPSPC (Россия) и Geocluster (CGG, Франция), Focus (Paradigm, США), RadExPro (Россия).

Непосредственно набор процедур цифровой обработки $3 \mathrm{D}$ наблюдений сформирован на основе опыта адаптации технологий процессинга данных сейсморазведки 2D при решении задач картирования обособленных физико-геологических неоднородностей малых глубин (до 500 метров). К основным процедурам можно отнести полосовую, режекторную и обратную фильтрации, расчет и коррекцию кинематических поправок, расчет остаточных фазовых сдвигов по программам коррекции статических поправок, вычитание наиболее интенсивных поверхностных волн-помех, коррекцию формы сигнала, когерентную фильтрацию.

Пример сейсмограмм на разных стадиях обработки представлен на рис. 14. После каждого этапа в обязательном порядке выполнялось контрольное суммирование - STACK. Коррекция статических (STCOR) и кинематических поправок производилась неоднократно.

Основными результатом цифровой об-

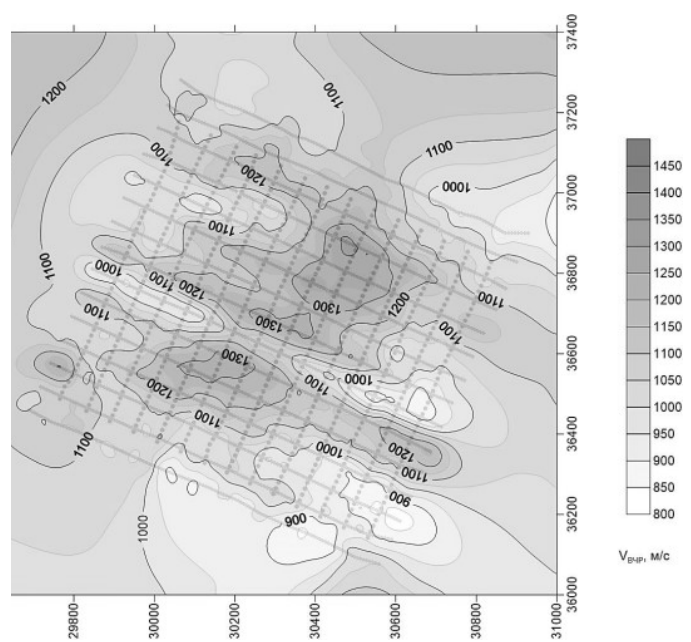

Рис. 15. Схема распределения скоростей в ВЧР на участке работ $3 D$ (от земной поверхности до уровня приведения +140 м) 
работки сейсморазведочных данных 3D является куб сейсмических данных, который вместе с кубами динамических атрибутов и кубами эффективных и интерваль- ных скоростей составляют информационную базу этапа интерпретации (рис. 16).

На срезах куба сейсмических данных по направлениям InLine (рис. 17 a, б, в)

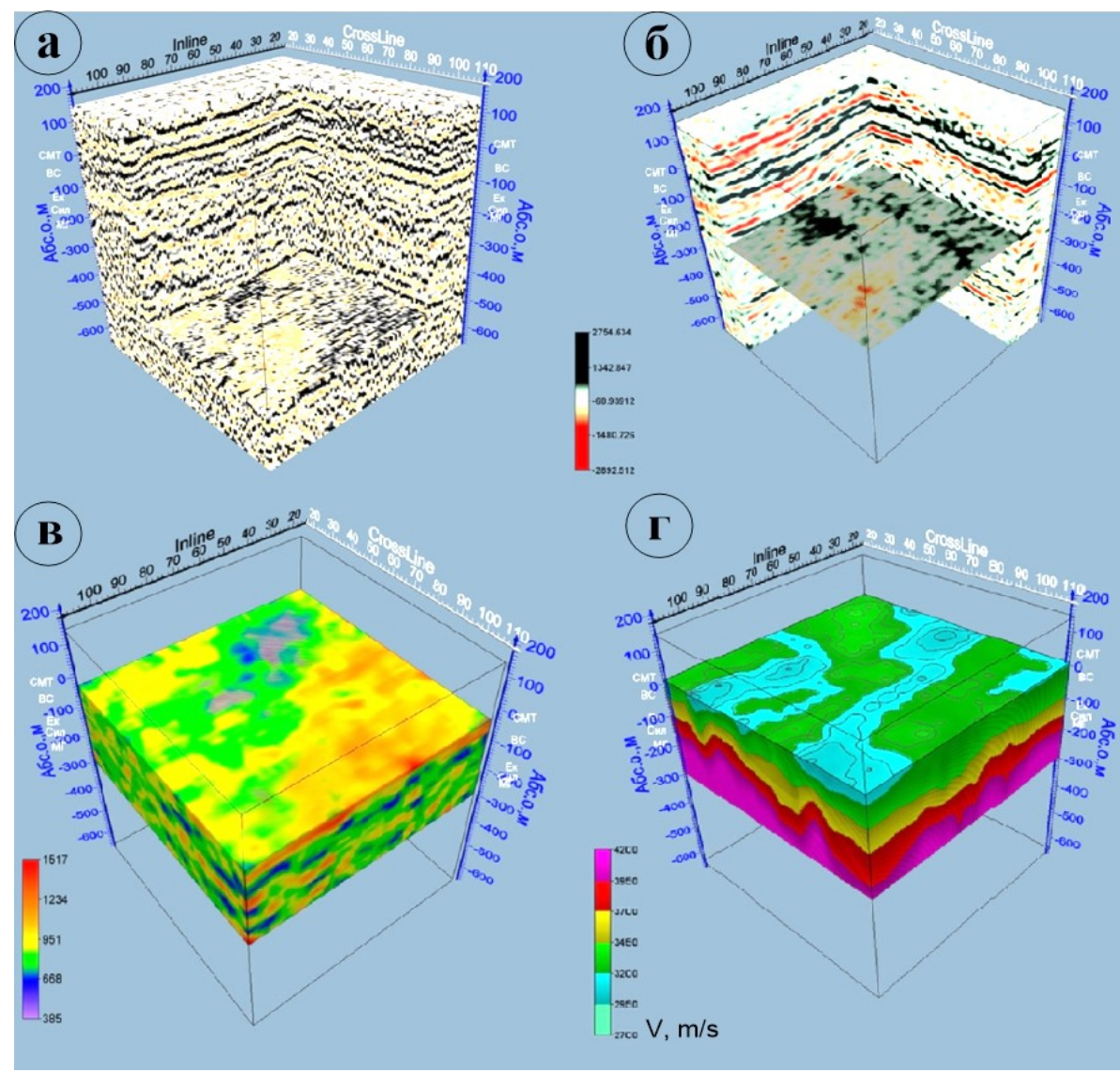

Рис. 16. Результаты ияифровой обработки сейсморазведочных данных $3 D$ : а) срезы трехмерного куба сейсмических данных; б) срезы динамического куба сейсмических данных; в) срез абсолютных значений амплитуд упругих колебаний на уровне отражающего горизонта $B C$;

г) срез трехмерного куба интервальных скоростей (интервал СМТ)
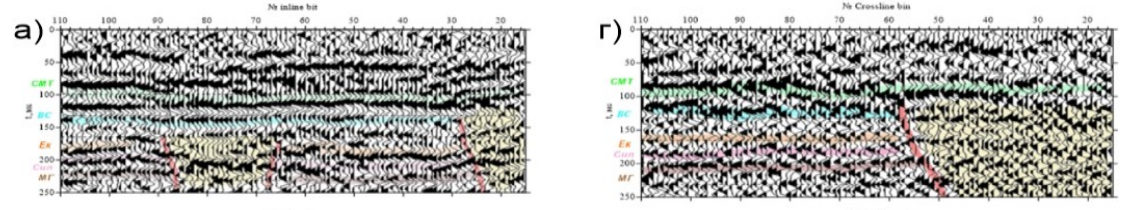

б)

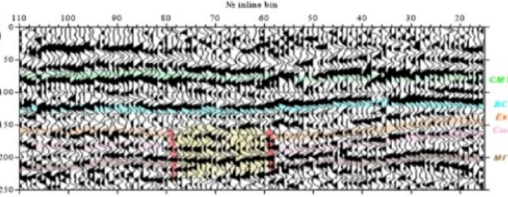

B)

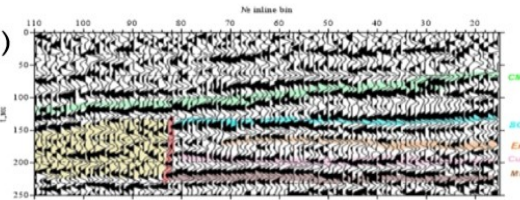

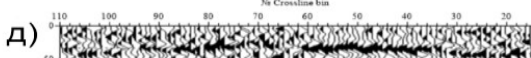

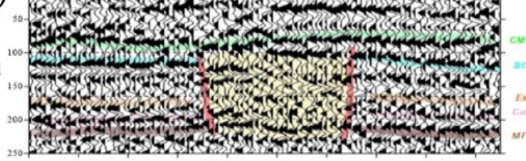

e)

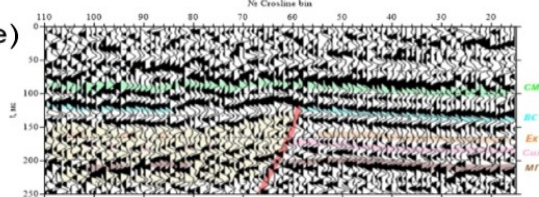

Рис.17. Вертикальеные срезы куба сейсмических данных в направлениях Inline u Crossline: a) Crossline Bin 104, б) Crossline Bin 64,

в) Crossline Bin 24, г) Inline Bin 110, d) Inline Bin 70, e) Inline Bin 29 
и CrossLine (рис. 17 г, д, е) отмечается ряд наиболее динамически выраженных осей синфазности, которые соответствуют целевым сейсмическим отражающим горизонтам (ОГ). Выделенные отражающие горизонты приурочены к кровле: соляно-мергельной толщи (СМТ), верхней соли (ВС), пласта карналлитовой зоны Е (Ек), сильвинитовой зоны (Сил) и интервалу маркирующей глины (МГ).

В отличие от временных разрезов 2D (см. рис. 2), полученных по результатам исследований прошлых лет в пределах изучаемой территории, результирующие суммы 3D характеризуются более низкочастотным спектром колебаний. Преобладающая частота суммарного волнового поля 3D составляет 60 Гц.

Выделенные по результатам 2D участки с осложнениями волнового поля (см. рис.2) согласуются с результатами обработки 3Dнаблюдений. Основные отличия обусловлены более высокой пространственной детальностью интерпретируемых линий с суммарными отражениями. Предельный шаг между данными линиями определяется размерами бина и составляет 8 м.

Подобная информационная насыщенность обосновывает возможность построения детальных пространственных моделей волнового поля и его атрибутов (см. рис. 16) и будет полезна на участках с высокой вероятностью наличия контрастных локально-обособленных физикогеологических неоднородностей, влияющих на устойчивость водозащитной толщи (ВЗТ). Подобного рода неоднородности пока не отмечались среди известных особенностей геологического строения. Традиционные геологические осложнения характеризуются зонами влияния и размерами, достаточными для выявления в том числе и сейсморазведкой $2 \mathrm{D}$ при плотности наблюдений не менее 5 км на 1 кв. км. Исключение составляют аварийные участки прорыва вод при «сквозном» нарушения целостности ВЗТ с образованием провалов земной поверхности.

Наряду с результатами качественной интерпретации получены площадные по- строения структурных поверхностей основных отражающих границ и распределение упругих свойств пород, разделяемых ими (рис. 18). Подобного рода информация наиболее приемлема для количественных оценок возможных негативных изменений структурно-физических параметров в пределах выделенных особенностей геологического строения В3Т.

Таким образом, многолетнее сотрудничество с предприятиями горнодобывающей отрасли Пермского края сформировало несколько приоритетных направлений развития геолого-геофизических методов опережающих исследований перспективных площадей и мониторинговых исследований аварийных объектов. Недоучет негативных геологических факторов при ведении горных работ на калийных рудниках, как показывает практика, может привести к катастрофическим последствиям вплоть до затопления рудника.

На сегодняшний день на территории Верхнекамского месторождения произошло несколько катастрофических событий с образованием провалов земной поверхности. Это требует от добывающих предприятий проведения мероприятий по ликвидации последствий аварий, а также инвестиций в строительство новых и расширение действующих рудников. Поэтому требуется активная разработка новых методических решений по прогнозу и контролю целостности породного массива $[3,4,5]$.

Пространственные системы регистрации упругих волн могут повысить информативность исследований за счет получения объемных детальных распределений структурно-физических параметров среды. Кроме того, получаемые параметры, обеспечивая геологические службы всесторонней информацией о состоянии изучаемой толщи пород, могут использоваться и при геомеханических расчетах устойчивости объектов исследований.

Итоговым результатом выполненного проекта является методика осуществления полного цикла площадных малоглубинных сейсморазведочных исследований: от проектирования оптимальной 

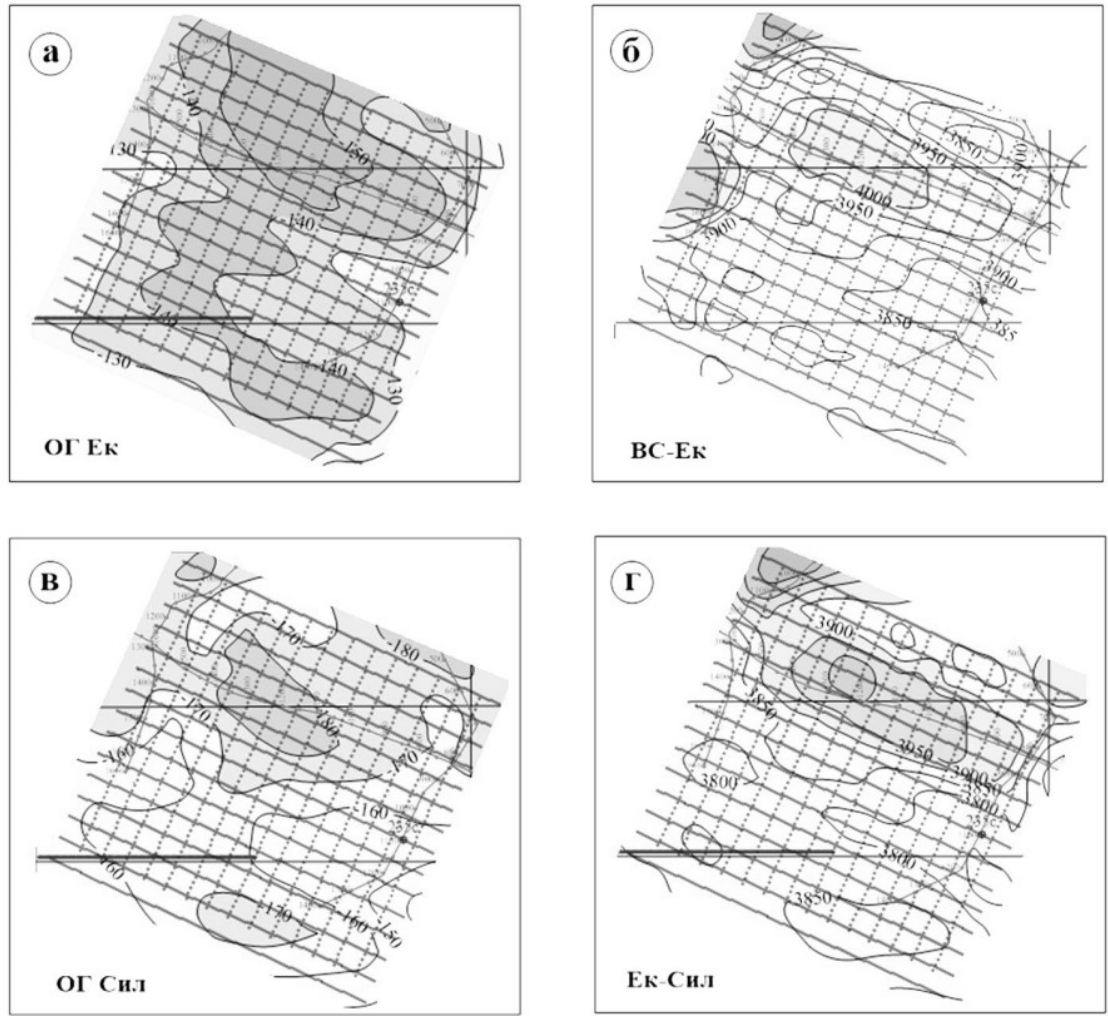

Рис. 18. Результаты сейсморазведочных $3 D$ исследований для интервалов ВС-Ек и Ек-Сил: а) - структурная схемы ОГ Ек; б) - скорости распространения волн в интервале ВС-Ек; в) - структурная схемы ОГ Сил; г) - скорости распространения волн в интервале Ек-Сил

пространственной системы сейсморазведочных исследований до её реализации, обработки и интерпретации полученных данных с целью обеспечения возможно- сти достоверной локализации физико-геологических неоднородностей при решении задач обеспечения безопасности ведения горных работ на ВКМКС.

\section{Библиографический список}

1. Осипов В.И., Барях А.А., Санфиров И.А., Мамаев Ю.А., Ястребов А.А. Карстовая опасность при затоплении калийного рудника в г. Березники Пермского края Российской Федерации / Геоэкология, инженерная геология, гидрогеология, геокриология. - 2014. - № 4. - С.356-361.

2. Санфиров И.А. Рудничные задачи сейсморазведки МОГТ: - Екатеринбург: УрО РАН, 1996. - 165 с.

3. Санфиров И.А., Глебов С.В., Ярославцев А.Г., Жикин А.А., Герасимова И.Ю. О перспективах малоглубинной сейсморазведки 3D на Верхнекамском месторождении солей // Геофизика. - 2015. №5. - C. 6-11.

4. Ярославцев А.Г., Бобров В.Ю., Жикин А.А. Инженерная сейсморазведка 3D на подработанной территории // Материалы 13-й конференции и выставки Инженерная геофизика 2017. [Электронный pecypc] - URL: http://www.earthdoc.org/publication/publicationdetails/?publication=88132.

5. Sanfirov I.A., Babkin A.I., Chugaev A.V., Ladeishcikov S.V. New methodical solutions for shallow-depth seismic surveying at deposits of water-soluble mineral resources // Eurasian mining (Gornyi Zhurnal). 2013. - №2. - P.7-11. 


\title{
SHALLOW 3D SEISMIC SURVEY ON THE SITES OF COMPLEX GEOLOGICAL STRUCTURE
}

\author{
Sanfirov I.A., Zhikin A.A., Yaroslavtsev A.G., \\ Babkin A.I., Chugaev A.V., Gerasimova I.U. \\ Mining Institute UB RAS
}

The development of water-soluble fields in small depths range requires reliable means of forecasting strength properties and monitoring the conditions of both commercial beds and the overlying strata. The article estimates the opportunities for advanced methodological solutions to identifying geological structure features that influence the underground mining safety at the Verkhnekamskoye potassium salt deposit.

Keywords: spatial seismic data acquisition systems, 3D seismic survey.

\section{Сведения об авторах}

Санфиров Игорь Александрович, доктор технических наук, директор Горного института УрО РАН филиал Пермского федерального исследовательского центра УрО РАН (ГИ УрО РАН), 614007, г. Пермь, ул. Сибирская 78-A; e-mail: sanf@mi-perm.ru

Жикин Александр Андреевич, исполняющий обязанности младшего научного сотрудника, ГИ УрО PAH; e-mail: alexzhikin@gmail.com

Ярославиев Александр Геннадьевич, кандидат технических наук, заведующий сектором МСАП ГИ УрО РАН; e-mail: asa_gis@mi-perm.ru

Бабкин Андрей Иванович, кандидат технических наук, заведующий сектором ЭСА ГИ УрО РАН; e-mail: aib@mi-perm.ru

Чугаев Александр Валентинович, кандидат технических наук, научный сотрудник ГИ УрО РАН; e-mail: chugaev@mi-perm.ru

Герасимова Ирина Юрьевна, кандидат технических наук, старший научный сотрудник, ГИ УрО PAH; e-mail: gerasimova@mi-perm.ru 